\title{
Applied environmental stresses to enhance the levels of polyphenolics in leaves of hawthorn plants
}

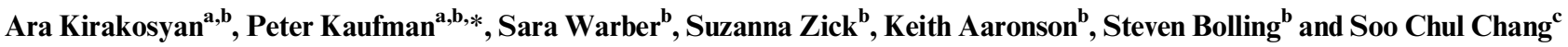 \\ a Department of Molecular, Cellular, and Developmental Biology, University of Michigan, Ann Arbor, MI 48109-1048, USA \\ ${ }^{\mathrm{b}}$ Michigan Integrative Medicine Program (MIM), University of Michigan, Ann Arbor, MI 48109, USA \\ ${ }^{\mathrm{c}}$ University College, Yonsei University, Seoul 120-749, Korea \\ *Corresponding author,e-mail: pbk@umich.edu
}

Received 22 August 2003; revised 21 January 2004

In this investigation, two species of Crataegus (hawthorn) were chosen because their polyphenolic constituents have recently received greater attention for the treatment of patients with severe heart disease. One-year-old plants of hawthorn (Crataegus laevigata and C. monogyna) were subjected to water-deficit (continuous water deprivation), cold $\left(4^{\circ} \mathrm{C}\right)$, flooding (immersion of roots of plants in water) or herbivory (leaf removal) stress treatments (each of 10 days duration) in order to assess their effects on levels of polyphenolics, namely (-)-epicatechin, catechin, chlorogenic acid, vitexin, vitexin- $\mathbf{2}^{\prime \prime}-O$-rhamnoside, acetylvitexin- $2^{\prime \prime}$ - $O$-rhamnoside, hyperoside, quercetin, and rutin in the leaves. The working hypothesis followed is that one or more of these stress treatment will elicit increases in the levels of these poly- phenolics. Cold stress causes increases in levels of vitexin$2^{\prime \prime}$ - $O$-rhamnoside, acetylvitexin-2 ${ }^{\prime \prime}$ - $O$-rhamnoside, hyperoside, and quercetin in both Crataegus species. Water-deficit stress increased the productivity of chlorogenic acid, catechin, and (-)-epicatechin in both hawthorn species. Flooding and herbivory caused no net increases, and in some cases, decreases in levels of polyphenolics. These studies indicate that either water-deficit stress or cold stress treatments, or a combination of the two, can be used to enhance the levels of desired polyphenolics in the leaves of these two hawthorn species in a photobioreactor system. These results may have significance for hawthorn in adapting to water-deficit or cold stress and are important considerations for the use of hawthorn in the treatment of heart disease in humans.

\section{Introduction}

Hawthorn (Crataegus spp.) leaves, flowers, and both green (unripe) and red (ripe) berries are used to make herbal preparations to treat patients with severe heart disease. The two species of hawthorn used to make such medicinal preparations are Crataegus laevigata (native to Europe and North America) and Crataegus monogyna (native to Europe, Asia, and North Africa) (Sticher and Meier 1998).

Some secondary metabolites synthesized in Crataegus (hawthorn) species have recently received attention, especially due to their vasoactive properties (Weihmayr and Emst 1996). Hawthorn extracts have also been shown to increase myocardial contractility, reduce reperfusion arrhythmias, dilate peripheral arteries, and mildly decrease blood pressure (Von Eiff et al. 1994, Weihmayr and Emst 1996, Zhang et al. 2001). When standardized extracts of the leaves and flowers have been used for treatment of patients with chronic heart failure, no significant adverse side-effects have been reported (Ody 1993, Sticher and Meier 1998). A standardized extract of the leaves and flowers is approved by the German Commission $\mathrm{E}$ for treatment of heart failure (Sticher and Meier 1998). It is widely used in Europe, especially in Germany, as a cardiotonic in the treatment of chronic heart failure, and high blood pressure (Schussler et al. 1995, Weihmayr and Emst 1996).

Many phenolic compounds in these plants possess antioxidant activity and may help protect cells against the oxidative damage caused by free radicals (Rakotoarison et al. 1997, Zhang et al. 2001, Kirakosyan et al. 2003).

Abbreviations - TFA, trifluoroacetic acid. 
The mechanisms of action of these protective effects of hawthorn extracts are still unclear and have not been fully characterized.

The phytoactive secondary compounds present in hawthorn leaves, flowers, and fruits are flavonol derivatives and flavonoids (Ammon and Kaul 1994, Rehwald 1995, Rohr and Meier 1997, Chang et al. 2001). The flavonols are chains of catechin and/or (-)-epicatechin linked by $4 \rightarrow 8$ or $4 \rightarrow 6$ bonds. The primary flavonoids present in hawthorn include, vitexin- $2^{\prime \prime}-O$-rhamnoside, acetylvitexin- $2^{\prime \prime}-O$ - rhamnoside, vitexin, isovitexin, quercetin, hyperoside, and rutin (Rehwald 1995, Sticher and Meier 1998).

However, even though there are a number of recent studies on the effects of abiotic stress treatments on gene expression, regulation by transcription factors, and crosstalk in calcium-mediated signal transduction pathways (Dubouzet et al. 2003, Shinozaki et al. 2003, Chinnusamy et al. 2004) in different plants, there is little information available regarding the effects of environmental stress treatments on the production of polyphenolics in Crataegus with the exception of a recent report by Kirakosyan et al. (2003) on effects of cold and drought stress on antioxidant activity of polyphenols in hawthorn.

The primary goal of the present study is to determine whether the levels of polyphenolics present in leaves of 1-year-old plants of C. laevigata and C. monogyna can be elevated by the use of environmental stress treatments. The stress treatments we employed included waterdeficit, cold, flooding, and herbivory. Our working hypothesis is that some of these environmental stress treatments will enhance levels of secondary metabolites, such as flavanol type substances and flavonoids, in hawthorn leaves. If this hypothesis is true, then such environmental stress treatments can be used as part of a photobioreactor system (Shotipruk et al. 1999) to produce consistently high levels of the active constituents in hawthorn leaves throughout the year.

\section{Materials and methods}

\section{Plant material}

One-year-old dormant plants of C.laevigata and C.monogyna were obtained from Lawyer Nursery, Plains, Montana, USA. Upon arrival of the dormant plants, shipped bare-root, individual plants were potted in 15-cm-diameter pots for C. laevigata and C. monogyna, using Sunshine Mix ${ }^{\circledR}$ No. 4 (Sun Gro Horticulture Inc., Bellview, WA, USA) as a potting medium. The plants were watered daily and kept at $25^{\circ} \mathrm{C}$ and illuminated continuously with high pressure sodium vapour lamps from P/L Light Systems Canada, Inc. (Grimsby, Ontario, Canada) with $1500 \mu \mathrm{mol} \mathrm{m}^{-2} \mathrm{~s}^{-1}$ irradiance (measured with a Li-Cor photon flux density meter; LiCor Inc., Lincoln, NE, USA) at the tops of the plants for 3months while the plants were breaking bud dormancy and developing fully expanded leaves.

\section{Nature of stress treatments}

All stress treatments were of 10 days duration, using six plants of each species per treatment. Leaf samples were obtained at time zero and at the end of 10 days for the respective treatments. The following stress treatments were used: (1) flooding (immersion of pots in water) versus no flooding (watering of plants daily) with comparable temperature $\left(25^{\circ} \mathrm{C}\right)$ and irradiance of $\left.1500 \mu \mathrm{mol} \mathrm{m}^{-2} \mathrm{~s}^{-1}\right)$ for both regimes; (2) water deficit stress for 10 days versus watering daily with comparable temperature $\left(25^{\circ} \mathrm{C}\right)$ and irradiance of $1500 \mu \mathrm{mol} \mathrm{m}^{-2} \mathrm{~s}^{-1}$ ) for both regimes; (3) herbivory (removal of half of every leaf on each plant by cutting off the distal halves) versus no herbivory (leaves intact) with comparable temperature $\left(25^{\circ} \mathrm{C}\right)$ and irradiance of $\left(1500 \mu \mathrm{mol} \mathrm{m}^{-2} \mathrm{~s}^{-1}\right)$ for both regimes; and (4) cold $\left(4^{\circ} \mathrm{C}\right)$ versus room temperature $\left(25^{\circ} \mathrm{C}\right)$ with comparable irradiance $\left(1500 \mu \mathrm{mol} \mathrm{m}^{-2} \mathrm{~s}^{-1}\right)$ for both regimes.

\section{Determination of soil moisture levels for water-deficit stress treatments}

For the water-deficit stress treatments, moisture levels of the soil were assayed gravimetrically. For this purpose, control plants were watered daily with $100 \mathrm{ml}$ deionized water over the 10-day treatment period, and the soil medium moisture content was determined at day zero and again at day 10. Water-deficit-stressed plants received no water during the 10-day treatment period, and the soil medium moisture content was determined at day zero and again at day 10 at the same time as for the control plants. Soil medium samples were obtained by sampling soil medium from each of the six pots of plants used per treatment. The aggregate weight of each sample used for analysis before drying was equal to $12-13 \mathrm{~g}$. Soil medium dry weights were determined after drying the respective samples for $24 \mathrm{~h}$ in an oven set at $46^{\circ} \mathrm{C}$. The soil medium used in this study was Professional Sunshine ${ }^{\circledR}$ Growing Mix No. 1 (Sun Gro Horticulture, Inc., Bellview, WA, USA). It consists of $70-80 \%$ Canadian sphagnum peat moss, perlite, dolomitic limestone (for $\mathrm{pH}$ adjustment) and wetting agent.

\section{Collection of leaf samples and extraction protocol}

At harvest time, leaves on each plant were cut off at the base of the petioles, the leaves from the six plants were pooled together, and frozen at $-80^{\circ} \mathrm{C}$ until time of extraction.

The extraction protocol was as follows: freeze-dried hawthorn leaves (approximately $15 \mathrm{~g}$ fresh weight) were lyophilized. The dried leaves (approximately $1 \mathrm{~g}$ dry weight) were powdered using a clean mortar and pestle. $0.5 \mathrm{~g}$ of the prepared powder was extracted in $10 \mathrm{ml}$ of dichloromethane overnight in $15 \mathrm{ml}$ pyrex tubes with screw caps mounted on a shaker (150 r.p.m), placed in an incubator set at $50^{\circ} \mathrm{C}$. The dichloromethane was poured off and the residue was extracted with $10 \mathrm{ml}$ of $70 \%$ methanol overnight with the tubes placed on a shaker set at 150 r.p.m. in a $50^{\circ} \mathrm{C}$ incubator. After removing the methanol by 
Table 1. Levels of polyphenolics ( $\mathrm{mg} \mathrm{g}^{-1}$ dry weight biomass) in Crataegus laevigata subjected to environmental stress treatments. $\mathrm{n}=3$; values are means \pm SD. Values showing the same index in the same row are not significantly different $(P>0.05)$.

\begin{tabular}{|c|c|c|c|c|c|c|}
\hline Compounds & $\mathrm{T}_{0}$ & $\begin{array}{l}\text { Control } \\
\left(\mathrm{T}_{10}\right)\end{array}$ & $\begin{array}{l}\text { Water-deficit } \\
\text { stress }\end{array}$ & $\begin{array}{l}\text { Cold } \\
\text { stress }\end{array}$ & $\begin{array}{l}\text { Flooding } \\
\text { stress }\end{array}$ & $\begin{array}{l}\text { Herbivory } \\
\text { stress }\end{array}$ \\
\hline Chlorogenic acid & $0.046 \pm 0.017^{\mathrm{A}}$ & $0.112 \pm 0.034^{\mathrm{B}}$ & $0.192 \pm 0.021^{C}$ & $0.068 \pm 0.014^{\mathrm{D}}$ & $0.106 \pm 0.042^{\mathrm{B}}$ & $0.041 \pm 0.007^{\mathrm{A}}$ \\
\hline Catechin & $0.523 \pm 0.029^{\mathrm{A}}$ & $0.309 \pm 0.091^{\mathrm{B}}$ & $3.139 \pm 0.168^{\mathrm{C}}$ & $0.443 \pm 0.027^{\mathrm{D}}$ & $0.290 \pm 0.044^{\mathrm{B}}$ & $0.132 \pm 0.054^{\mathrm{E}}$ \\
\hline (-)-epicatechin & $0.345 \pm 0.024^{\mathrm{A}}$ & $0.359 \pm 0.035^{\mathrm{A}}$ & $2.402 \pm 0.114^{\mathrm{B}}$ & $0.351 \pm 0.022^{\mathrm{A}}$ & $0.249 \pm 0.032^{\mathrm{C}}$ & $0.172 \pm 0.012^{\mathrm{D}}$ \\
\hline Vitexin & $0.072 \pm 0.005^{\mathrm{A}}$ & $0.056 \pm 0.009^{\mathrm{B}}$ & $0.168 \pm 0.012^{\mathrm{C}}$ & $0.126 \pm 0.009^{\mathrm{D}}$ & $0.023 \pm 0.003^{\mathrm{E}}$ & $0.041 \pm 0.009^{\mathrm{B}}$ \\
\hline $\begin{array}{l}\text { Vitexin- } 2^{\prime \prime}- \\
O \text {-rhamnoside }\end{array}$ & $1.696 \pm 0.075^{\mathrm{A}}$ & $1.707 \pm 0.314^{\mathrm{A}}$ & $1.833 \pm 0.094^{\mathrm{B}}$ & $2.433 \pm 0.11^{\mathrm{C}}$ & $0.696 \pm 0.047^{\mathrm{D}}$ & $1.150 \pm 0.096^{\mathrm{E}}$ \\
\hline $\begin{array}{l}\text { Acetylvitexin- } 2^{\prime \prime} \text { - } \\
O \text {-rhamnoside }\end{array}$ & $3.956 \pm 0.279^{\mathrm{A}}$ & $4.036 \pm 0.688^{\mathrm{A}}$ & $2.036 \pm 0.162^{\mathrm{B}}$ & $12.130 \pm 0.83^{C}$ & $4.722 \pm 0.323^{\mathrm{D}}$ & $3.290 \pm 0.261^{\mathrm{E}}$ \\
\hline Hyperoside & $0.101 \pm 0.014^{\mathrm{A}}$ & $0.199 \pm 0.047^{\mathrm{B}}$ & $0.491 \pm 0.052^{\mathrm{C}}$ & $1.475 \pm 0.095^{\mathrm{D}}$ & $0.411 \pm 0.026^{\mathrm{E}}$ & $0.118 \pm 0.012^{\mathrm{A}}$ \\
\hline Quercetin & $0.050 \pm 0.004^{\mathrm{A}}$ & $0.049 \pm 0.009^{\mathrm{A}}$ & $0.003 \pm 0.001^{\mathrm{B}}$ & $0.156 \pm 0.013^{\mathrm{C}}$ & $0.055 \pm 0.003^{\mathrm{A}}$ & $0.035 \pm 0.002^{\mathrm{D}}$ \\
\hline Rutin & $0.049 \pm 0.013^{\mathrm{A}}$ & $0.081 \pm 0.011^{\mathrm{B}}$ & $0.514 \pm 0.046^{C}$ & $0.170 \pm 0.011^{\mathrm{D}}$ & $0.078 \pm 0.006^{\mathrm{B}}$ & $0.035 \pm 0.008^{\mathrm{A}}$ \\
\hline
\end{tabular}

air-drying, the remaining water layer was separated from the precipitate by centrifugation at $10000 \times g$ for $10 \mathrm{~min}$. The extraction of the precipitates was subsequently performed twice with $5 \mathrm{ml}$ aliquots of diethyl ether and $10 \mathrm{ml}$ ethyl acetate. The remaining water layer was dissolved in $6 \mathrm{ml}$ distilled water, adjusted the $\mathrm{pH}$ to 5.4 with $o$-phosphoric acid, and incubated with $0.1 \mathrm{ml}$ distilled water containing $\beta$-glucosidase at $0.1 \mathrm{mg}$ of the enzyme per $0.1 \mathrm{ml}$ water. The mixture was incubated for $1 \mathrm{~h}$ in a water bath set at $35^{\circ} \mathrm{C}$ in order to release flavonoids from sugar conjugates. Ten millilitres of $100 \%$ methanol was then added to the mixture to dissolve the flavonoids more effectively. Following repeated mixing, the tubes were then placed on a shaker at 150 r.p.m. for $60-90 \mathrm{~min}$ in an incubator set at $60^{\circ} \mathrm{C}$. The mixture was then centrifuged and the supernatant was evaporated using a Büchi evaporator. The residues from all steps were combined together and dissolved in $10 \mathrm{ml}$ of $80 \%$ methanol. After filtration through a $0.22-\mu \mathrm{m}$ filter, the extracts were ready for high performance liquid chromatography (HPLC) analysis.

\section{HPLC analysis of extracts}

The following conditions were used for HPLC analysis: a Phenomenex Luna ${ }^{\mathrm{TM}}$ column $[5 \mu \mathrm{m}$ pore size, C-18, $150 \mathrm{~mm} \times 4.60 \mathrm{~mm}$ ], flow rate of $1 \mathrm{ml} \mathrm{min}^{-1}$; solvent $\mathrm{A}$ [water $+0.1 \%$ TFA (trifluoroacetic acid)], solvent $\mathrm{B}$ (acetonitrile $+0.1 \%$ TFA); the HPLC running conditions consisted of a gradient of $5 \%$ B to $100 \%$ B during a $30 \mathrm{~min}$ period; the oven temperature was $40^{\circ} \mathrm{C}$. A 10 - $\mu$ l aliquot of sample was injected onto a Shimadzu 10 AD HPLC system with a SPDM-10AV photodiode array detector (Shimadzu Scientific Instruments Inc., Columbia, MD, USA). The quantitative analysis of each compound in the extracts was analysed by comparison with the corresponding authentic samples. Detection was set at $280 \mathrm{~nm}$.

\section{Statistical analysis of data}

All treatments were replicated three times. Results are given as mean \pm standard deviation (SD). Data were analysed using ANOVA to determine differences between treatment means. Means were separated by Tukey's significant difference test $(P<0.05)$.

\section{Sources of chemicals}

Solvents employed for extraction and HPLC analysis were obtained from Fisher Scientific Co. (Pittsburgh, PA, USA), $\beta$-glucosidase from Sigma Chemical Co. (St. Louis, MO, USA), flavonoid standards from Indofine Chemical Co. (Somerville, NJ, USA), and (-)-epicatechin, catechin, vitexin- $2^{\prime \prime}-O$-rhamnoside and acetylvitexin- $2^{\prime \prime}$ $O$-rhamnoside from Dr Friederich Lang, Head, Analytical Department, Dr Willmar Schwabe $\mathrm{BmbH}$ and Co. Karlsruhe, Germany.

\section{Results}

The results of HPLC analysis of the levels of polyphenolics in C.laevigata and C.monogyna are presented in Tables 1 and 2, respectively, for water-deficit stress, cold stress, flooding stress and simulated herbivory stress treatments. The data presented in these tables are compared for levels of the respective compounds at initiation of the stress treatment (indicated as $\mathrm{T}_{0}$ ) and at the end of 10 days for the control $\left(\mathrm{T}_{10}\right)$ and stressed plants, respectively.

Significant increases in the levels of (-)-epicatechin and catechin, are evident for both Crataegus species following water-deficit stress treatment, especially for C.laevigata. Chlorogenic acid also increased, more in C. monogyna than in C.laevigata. Among the flavonoids, in C.laevigata, only vitexin, hyperoside, and rutin levels increased following water-deficit stress, whereas acetylvitexin- $2^{\prime \prime}$ - $O$-rhamnoside level decreased more than $50 \%$, and levels of the other flavonoid representatives did not change appreciably. For C. monogyna, no major changes are evident in levels of flavonoids with the exception of acetylvitexin- $2^{\prime \prime}-O$-rhamnoside $(50 \%$ decrease) and rutin (five-fold increase) when one compares control with water-deficit stress. In summary, the primary effect of water-deficit stress is to enhance the levels of catechin especially and (-)-epicatechin in the leaves of both hawthorn species. In addition, gravimetric data and percentage soil moisture values from the soil medium moisture determinations for both control and 10-day, water-deficit stress treatments indicate that at day 0 , soil medium water content varied between 80 and $82 \%$ for both hawthorn species (Table 3). After 10 days, the 
Table 2. Levels of polyphenolics ( $\mathrm{mg} \mathrm{g}^{-1}$ dry weight biomass) in Crataegus monogyna subjected to environmental stress treatments. $\mathrm{n}=3$; values are means \pm SD. Values showing the same index in the same row are not significantly different $(P>0.05)$.

\begin{tabular}{|c|c|c|c|c|c|c|}
\hline Compounds & $\mathrm{T}_{0}$ & $\begin{array}{l}\text { Control } \\
\left(\mathrm{T}_{10}\right)\end{array}$ & $\begin{array}{l}\text { Water-deficit } \\
\text { stress }\end{array}$ & $\begin{array}{l}\text { Cold } \\
\text { stress }\end{array}$ & $\begin{array}{l}\text { Flooding } \\
\text { stress }\end{array}$ & $\begin{array}{l}\text { Herbivory } \\
\text { stress }\end{array}$ \\
\hline Chlorogenic acid & $0.017 \pm 0.009^{\mathrm{A}}$ & $0.057 \pm 0.012^{\mathrm{B}}$ & $0.362 \pm 0.039^{\mathrm{C}}$ & $0.042 \pm 0.015^{\mathrm{B}}$ & $0.183 \pm 0.012^{\mathrm{D}}$ & $0.111 \pm 0.014^{\mathrm{E}}$ \\
\hline Catechin & $0.291 \pm 0.035^{\mathrm{A}}$ & $0.351 \pm 0.086^{\mathrm{B}}$ & $1.544 \pm 0.212^{\mathrm{C}}$ & $0.215 \pm 0.018^{\mathrm{D}}$ & $0.678 \pm 0.018^{\mathrm{E}}$ & $0.417 \pm 0.024^{\mathrm{B}}$ \\
\hline (-)-epicatechin & $0.340 \pm 0.024^{\mathrm{A}}$ & $0.525 \pm 0.091^{\mathrm{B}}$ & $0.905 \pm 0.071^{\mathrm{C}}$ & $0.358 \pm 0.026^{\mathrm{A}}$ & $0.444 \pm 0.036^{\mathrm{D}}$ & $0.588 \pm 0.046^{\mathrm{B}}$ \\
\hline Vitexin & $0.064 \pm 0.005^{\mathrm{A}}$ & $0.118 \pm 0.044^{\mathrm{B}}$ & $0.111 \pm 0.03^{\mathrm{B}}$ & $0.096 \pm 0.008^{\mathrm{B}}$ & $0.019 \pm 0.005^{\mathrm{C}}$ & $0.139 \pm 0.025^{\mathrm{B}}$ \\
\hline $\begin{array}{l}\text { Vitexin- } 2^{\prime \prime} \text { - } \\
O \text {-rhamnoside }\end{array}$ & $1.238 \pm 0.099^{\mathrm{A}}$ & $1.046 \pm 0.154^{\mathrm{B}}$ & $0.925 \pm 0.048^{\mathrm{B}}$ & $5.198 \pm 0.391^{\mathrm{C}}$ & $0.715 \pm 0.055^{\mathrm{D}}$ & $0.977 \pm 0.075^{\mathrm{B}}$ \\
\hline $\begin{array}{l}\text { Acetylvitexin } 2^{\prime \prime}- \\
O \text {-rhamnoside }\end{array}$ & $9.022 \pm 0.773^{\mathrm{A}}$ & $6.578 \pm 0.789^{B}$ & $3.597 \pm 0.168^{\mathrm{C}}$ & $8.097 \pm 0.685^{\mathrm{D}}$ & $4.685 \pm 0.211^{\mathrm{E}}$ & $4.983 \pm 0.038^{\mathrm{F}}$ \\
\hline Hyperoside & $0.424 \pm 0.038^{\mathrm{A}}$ & $0.469 \pm 0.041^{\mathrm{B}}$ & $0.431 \pm 0.027^{\mathrm{A}}$ & $2.292 \pm 0.188^{C}$ & $0.464 \pm 0.051^{\mathrm{B}}$ & $0.548 \pm 0.033^{\mathrm{D}}$ \\
\hline Quercetin & $0.018 \pm 0.006^{\mathrm{A}}$ & $0.047 \pm 0.008^{\mathrm{B}}$ & $0.092 \pm 0.007^{\mathrm{C}}$ & $0.064 \pm 0.004^{\mathrm{D}}$ & $0.081 \pm 0.009^{\mathrm{C}}$ & $0.062 \pm 0.007^{\mathrm{D}}$ \\
\hline Rutin & $0.026 \pm 0.005^{\mathrm{A}}$ & $0.072 \pm 0.011^{\mathrm{B}}$ & $0.357 \pm 0.043^{\mathrm{C}}$ & $0.071 \pm 0.008^{\mathrm{B}}$ & $0.044 \pm 0.006^{\mathrm{D}}$ & $0.320 \pm 0.027^{\mathrm{C}}$ \\
\hline
\end{tabular}

soil moisture content for the control plants averaged $84.2 \%$, whereas for the water-deficit treatment plants, it had dropped to an average of $25.4 \%$ moisture, a difference of $59 \%$. There was a greater percentage decrease in soil medium moisture content for C.monogyna than for C.laevigata at the end of the 10-day treatment period.

Cold stress treatment actually maintained levels of chlorogenic acid, catechin and (-)-epicatechin at similar levels as for the controls in both C.laevigata and C.monogyna. On the other hand, flavonoid levels, for all compounds (except vitexin, quercetin, and rutin in C. monogyna), were significantly increased for both hawthorn species following cold stress treatment.

When we compare the effects of water-deficit and cold stress treatments, important differences in secondary metabolite levels in hawthorn leaves are evident. Water-deficit stress significantly enhanced levels of flavanol type substances and had no major effects on the levels of flavonoids, whereas cold stress treatment had just the opposite effect.

The other abiotic stress treatments employed, namely, flooding stress and simulated herbivory stress, cause no major increases in levels of polyphenolics in hawthorn leaves. For example, flooding stress treatment for 10 days either caused no significant changes in levels of most polyphenolics, a slight increase (hyperoside in C.laevigata and chlorogenic acid, catechin, and quercetin in C.monogyna), or they decreased in amounts. Some differences are evident between $C$. laevigata and C.monogyna regarding the effects of simulated herbivory stress treatment. Chlorogenic acid, catechin and (-)-epicatechin levels dropped significantly for $C$. laevigata, but actually showed no major changes in C.monogyna. For the flavonoids, no major changes in levels occurred except for the large decreases in acetylvitexin-2" $-O$-rhamnoside in C. laevigata and C. monogyna.

\section{Discussion}

Water deficits and cold stress are major environmental factors which limit the productivity of plants (biomass accumulation). Plants have developed biochemical and physiological mechanisms to respond and adapt to these stresses in order to survive. These mechanisms involve stress-inducible genes that directly protect against such environmental stresses or act to regulate gene expression and cross-talk in signal transduction pathways (Seki et al. 2003, Chinnusamy et al. 2004).

In this connection, there are a number of reports on mechanisms by which abiotic stress treatments regulate synthesis of secondary metabolites in plants. These mechanisms involve differential mRNA accumulation in Arabidopsis phenotypes using transcriptome profiles (Provart et al. 2003), cold stress-induced differential gene expression in Arabidopisis leaves using serial analysis of gene expression patterns (SAGE) (Jung et al. 2004).

The mechanisms by which cold and drought stress up-regulate the biosynthesis of polyphenolics in hawthorn are essentially unknown, but some of the molecular genetic approaches used by other investigators, as cited above, may be helpful in unravelling them.

Based on the results of the present study, cold or water-deficit stress treatments may constitute a highly effective way to enhance the levels of polyphenolics. The same can be said for antioxidant activity in hawthorn leaves (Kirakosyan et al. 2003). Such treatments may act by diverting photosynthetically fixed carbon from synthesis of primary metabolites such as cellulose, lignin, lipids, and proteins that are associated with growth metabolism to synthesis of secondary metabolites like flavonoids and flavanol-type substances that are associated

Table 3. Water contents ${ }^{\text {a }}$ of soil media for Crataegus laevigata and C.monogyna at day 0 and at day 10 following + and - drought stress treatments. ${ }^{a} \mathrm{n}=3$; values are means $\pm \mathrm{SD}$.

\begin{tabular}{|c|c|c|c|c|c|c|}
\hline Species and treatment & $\begin{array}{l}\text { Wet weight } \\
\text { (g) Day } 0\end{array}$ & $\begin{array}{l}\text { Dry weight } \\
\text { (g) Day } 0\end{array}$ & $\%$ water & $\begin{array}{l}\text { Wet weight } \\
\text { (g) day } 10\end{array}$ & $\begin{array}{l}\text { Dry weight } \\
\text { (g) day } 10\end{array}$ & $\%$ water \\
\hline C. laevigata control & $12.94 \pm 0.97$ & $2.59 \pm 0.18$ & 79.9 & $12.24 \pm 1.15$ & $2.04 \pm 0.18$ & 83.5 \\
\hline C. laevigata water-deficit stress & $12.20 \pm 0.89$ & $2.62 \pm 0.33$ & 78.5 & $3.43 \pm 0.29$ & $2.34 \pm 0.13$ & 31.7 \\
\hline C. monogyna control & $12.66 \pm 1.05$ & $2.71 \pm 0.34$ & 78.6 & $12.62 \pm 0.98$ & $1.90 \pm 0.11$ & 84.9 \\
\hline C.monogyna water-deficit stress & $12.52 \pm 1.12$ & $2.24 \pm 0.25$ & 82.1 & $3.29 \pm 0.27$ & $2.63 \pm 0.22$ & 20.0 \\
\hline
\end{tabular}


with little or no growth in water-deficit- and cold-stressed plants (Kaufman et al. 1999).

The present study provides a practical way to obtain consistent and high levels of polyphenolics from leaves of C.laevigata and C.monogyna year-round in a greenhouse photobioreactor system. Based on the results reported here, this system could employ the following protocols: (1) use of 1- to 2-year-old C.laevigata and C.monogyna plants obtained from a local nursery; (2) culture of plants in a greenhouse set for a temperature of $25^{\circ} \mathrm{C}$ and using high intensity sodium vapour lamps programmed for $24 \mathrm{~h}$ light per day and having a irradiance of at least $1500 \mu \mathrm{mol} \mathrm{m} \mathrm{m}^{-2} \mathrm{~s}^{-1}$ at the tops of the plants placed one meter from the light source; (3) after leaves have fully developed, the plants can be subjected to cold stress treatment by placing them in a cold storage room set at $4{ }^{\circ} \mathrm{C}$ for 10 days or to drought stress for 10 days by withholding the daily water supply to the plants; (4) at the end of the stress treatment, leaves can be harvested from the plants and freeze-dried; (5) re-growing the plants in the greenhouse for a second cycle of stress treatment and leaf harvest; (6) re-cycling the plants outdoors after the second leaf harvest; and (7) starting another group of hawthorn plants obtained from the commercial nursery for two new cycles of stress treatments and leaf harvests.

The above greenhouse photobioreactor protocol is not possible with nursery-grown hawthorn plants or natural plant populations. This is because of vagaries of the weather, herbivory and pathogen attack, a long dormant season of 6-8 months, and difficulty in the imposition of cold or drought stress treatments. The primary advantage that accrues from a greenhouse photobioreactor system for producing phytopharmaceutical compounds such as polyphenolics from the leaves of hawthorn plantlets, is that one can now obtain a good degree of quality control over the levels and kinds of medicinal products produced.

The photobioreactor greenhouse system has also been applied to other medicinal plants. These include peppermint, Mentha X piperita (Shotipruk et al. 1999), tree of joy, Camptotheca accuminata (Kaufman et al. 1999), and kudzu, Pueraria montana (Kaufman et al. 2002). However, the environmental parameters and stress treatments differ considerably from those used for hawthorn, Crataegus spp.

Acknowledgements - This study was supported by the University of Michigan NIH National Center for Complementary and Alternative Medicine grant I P50 AT00011 and by The Fulbright Program that funded A.K. as a Fulbright Fellow during this study. We express our thanks to Dr Freiderich Lang, Head, Analytical Department, Dr Willmar Schwabe Gmbh \& Co., Karlsruhe, Germany for providing us with samples of (-)-epicatechin, catechin, acetylvitexin- $2^{\prime \prime}-O$-rhamnoside and vitexin- $2^{\prime \prime}-O$-rhamnoside standards.

\section{References}

Ammon HPT, Kaul R (1994) Crataegus. Herz-kreislauf-wirkungen von Crataegusextrakten. Flavonoiden und procyanidinen.
Deutsche Apothek Zeitung 134: 2433-2436, 2521-2535, 2631-2636

Chang Q, Zhu M, Zuo Z, Chow M, Ho WK (2001) High-performance liquid chromatographic method for simultaneous determination of hawthorn active components of rat plasma. J Chromatogr B Biomed Sci Appl 760: 227-235

Chinnusamy V, Schumaker K, Zhu JK (2004) Molecular genetic perspectives on cross-talk and specificity in abiotic stress signalling in plants. J Exp Bot 55: 225-236

Dubouzet JG, Sakuma Y, Ito Y, Kasuga M, Dubouzet EG, Miura S, Seki M, Shinozaki K, Yamaguchi-Shinozaki K (2003) OsDREB genes in rice, Oryza sativa L., encode transcription activators that function in drought-, high-salt- and coldresponsive gene expression. Plant J 33: 751-763

Jung SH, Lee JY, Lee DH (2003) Use of SAGE technology to reveal changes in gene expression in Arabidopsis leaves undergoing cold stress. Plant Mol Biol 52: 553-567

Kaufman PB, Coon CW, Govil JN, Hoyt JE, Lu CR, Madsen BJ, Warber SL (2002) Creating a Sustainable Future. Living in Harmony With the Earth. Researchco Book Centre, New Delhi, India

Kaufman PB, Cseke LJ, Warber S, Duke JA, Brielmann HL (1999) Natural Products from Plants. CRC Press, Boca Raton, FL, USA

Kirakosyan A, Seymour E, Kaufman PB, Warber S, Bolling S, Chang SC (2003) Antioxidant capacity of polyphenoloc extracts from leaves of Crataegus laevigata and C. monogyna (hawthorn) subjected to drought and cold stress. J Agric Food Chem 51: 3973-3976

Ody P (1993) The Complete Medicinal Herbal. D.K. Publishing Inc, New York, USA

Pillai MA, Akiyama T (2004) Differential expression of an S-adenosyl-L-methionine decarboxylase gene involved in polyamine biosynthesis under low temperature stress in japonica and indica rice genotypes. Mol Genet Genomics 271: 141-145.

Provart NJ, Gil P, Chen W, Han B, Chang HS, Wang X, Zhu T (2003) Gene expression phenotypes of Arabidopsis associated with sensitivity to low temperatures. Plant Physiol 132: 893-906

Rakotoarison DA, Greissier B, Trotin F, Brunet C, Dine T, Luyckx M, Vasseur J, Cazin M, Cazin JC, Pinkas M (1997) Antioxidant activities of polyphenolic extracts from flowers, in vitro callus and cell suspension cultures of Crataegus monogyna. Pharmazie 52: 60-64

Rehwald A (1995) Analytical investigation of Crataegus species and Passiflora incarnata L. by high performance liquid chromatography. PhD Dissertation, Swiss Federal Institute of Technology, Zurich, Switzerland

Rohr G, Meier B (1997) Crataegus- Pharmazeutische qualitat und wirksamkeit. Deutsche Apothek Zeitung 137: 104-116

Schussler M, Holzl J, Fricke U (1995) Myocardial effects of flavonoids from Crataegus species. Arzneim-Forsch 45: 842-845

Seki M, Kamei A, Yamaguchi-Shinozaki K, Shinozaki K (2003) Molecular responses to drought, salinity and frost: common and different paths for plant protection. Curr Opin Biotechnol 14: 194-199

Shinozaki K, Yamaguchi-Shinozaki K, Seki M (2003) Regulatory network of gene expression in the drought and cold stress responses. Curr Opin Plant Biol 6: 410-417

Shotipruk A, Kaufman PB, Wang HY (1999) Conceptual design of LED-based hydroponic photobioreactor for high-density plant cultivation. Biotechnol Prog 15: 1058-1064

Sticher O, Meier B (1998) Hawthorn (Crataegus): Biological activity and new strategies for quality control. In: Lawson LD, Bauer R (eds) Phytomedicines of Europe. Chemistry and Biological Activity. American Chemical Society, Washington, D.C., ACS Symposium Series 691, pp. 241-262

Von Eiff M, Brunner H, Haegeli A, Kreuter U, Martina B, Meier B, Schaffner W (1994) Hawthorn/Passionflower extract and improvement in physical capacity of patients with dyspnoea Class II of the NYHM functional classification. Acta Therap 20: 47-66

Weihmayr T, Emst E (1996) Therapeutic effectiveness of Crataegus. Forschritte Med 114: 27-29

Zhang Z, Chang Q, Zhu M, Huang Y, Ho WKK, Chen Z-Y (2001) Characterization of antioxidants present in hawthorn fruits. J Nutr Biochem 12: 144-152

Edited by V. Hurry 